\title{
Individual Differences in Resting Corticospinal Excitability Are Correlated with Reaction Time and GABA Content in Motor Cortex
}

\author{
- Ian Greenhouse, ${ }^{1}{ }^{\oplus}$ Maedbh King, ${ }^{1}{ }^{\oplus}$ Sean Noah, ${ }^{1}{ }^{\oplus}$ Richard J. Maddock, ${ }^{2}$ and Richard B. Ivry ${ }^{1}$ \\ ${ }^{1}$ University of California, Berkeley, Berkeley, California 94720-1650, and ${ }^{2}$ University of California, Davis, Sacramento, California 95817
}

Individuals differ in the intrinsic excitability of their corticospinal pathways and, perhaps more generally, their entire nervous system. At present, we have little understanding of the mechanisms underlying these differences and how variation in intrinsic excitability relates to behavior. Here, we examined the relationship between individual differences in intrinsic corticospinal excitability, local cortical GABA levels, and reaction time (RT) in a group of 20 healthy human adults. We measured corticospinal excitability at rest with transcranial magnetic stimulation, local concentrations of basal GABA with magnetic resonance spectroscopy, and RT with a behavioral task. All measurements were repeated in two separate sessions, and tests of reliability confirmed the presence of stable individual differences. There was a negative correlation between corticospinal excitability and RT, such that larger motor-evoked potentials (MEPs) measured at rest were associated with faster RTs. Interestingly, larger MEPs were associated with higher levels of GABA in M1, but not in three other cortical regions. Together, these results suggest that individuals with more excitable corticospinal pathways are faster to initiate planned responses and have higher levels of GABA within M1, possibly to compensate for a more excitable motor system.

Key words: GABA; individual differences; inhibition; MR spectroscopy; reaction time; TMS

\section{Significance Statement}

This study brings together physiological, behavioral, and neurochemical evidence to examine variability in the excitability of the human motor system. Previous work has focused on state-based factors (e.g., preparedness, uncertainty), with little attention given to the influence of inherent stable characteristics. Here, we examined how the excitability of the motor system relates to reaction time and the regional content of the inhibitory neurotransmitter GABA. Importantly, motor pathway excitability and GABA concentrations were measured at rest, outside a task context, providing assays of intrinsic properties of the individuals. Individuals with more excitable motor pathways had faster reaction times and, paradoxically, higher concentrations of GABA. We propose that greater GABA capacity in the motor cortex counteracts an intrinsically more excitable motor system.

\section{Introduction}

Studies of behavior have generally focused on variables that influence the dynamics, i.e., state-based changes, of neural excitability during task performance. An extensive transcranial magnetic stimulation (TMS) literature has accumulated over the past 25 years describing changes in corticospinal (CS) excitability during the preparation and execution of responses (Starr et al., 1988; Pascual-

\footnotetext{
Received Oct. 7, 2016; revised Jan. 4, 2017; accepted Jan. 31, 2017

Author contributions: I.G., R.J.M., and R.B.I. designed research; I.G. and S.N. performed research; I.G. and R.J.M. contributed unpublished reagents/analytic tools; I.G., M.K., and S.N. analyzed data; I.G., M.K., S.N., R.J.M., and R.B.I. wrote the paper.

This work was supported by NIH Grant NS085570. We thank Ludovica Labruna, Ana Sias, and Timothy Hoang for assistance with data collection and the participants for their involvement.

Correspondence should be addressed to lan Greenhouse, 3201 Tolman Hall, University of California, Berkeley, Berkeley, CA 94720-1650. E-mail: igreenhouse@berkeley.edu.

DOI:10.1523/JNEUROSCI.3129-16.2017

Copyright $\odot 2017$ the authors $\quad 0270-6474 / 17 / 372686-11 \$ 15.00 / 0$
}

Leone et al., 1992; Hasbroucq et al., 1999; Leocani et al., 2000; Duque and Ivry, 2009; Duque et al., 2010; Greenhouse et al., 2015a,b). Variation in task performance has also been related to contextual, or state-based changes in task-independent factors: For example, variability in the compressive force of a response during a simple reaction time (RT) task can be explained by fluctuations in resting activity within somatomotor cortex (Fox et al., 2007). Although the hemodynamic measurements are acquired at rest, the strength of the signal is changing over time. This body of work has firmly established that these transient changes in the motor system are relevant to behavior, with activity increases predicting faster or more forceful actions.

However, transient changes in neural excitability may simply reflect the tip of the iceberg. Mostly overlooked in this literature has been the study of how variation in behavior relates to stable, trait-based individual differences. For example, averaged TMS measures of CS excitability taken at rest exhibit stable individual 
differences across testing sessions (Carroll et al., 2001; Kamen, 2004; Malcolm et al., 2006). To date, it is unknown whether individual differences in CS excitability relate to behavior.

In contrast, magnetic resonance spectroscopy (MRS) studies, in part because of relatively poor temporal resolution, have drawn attention to the relationships between individual differences in tonic neurotransmitter availability and motor excitability or behavior. MRS measurements of GABA concentrations in primary motor cortex (M1), taken at rest, correlated positively with RT, such that individuals with higher basal levels of M1 GABA tended to have slower RTs during the performance of a sequence learning task (Stagg et al., 2011a). Counterintuitively, individuals with more excitable CS pathways, measured with TMS, exhibited higher concentrations of M1 GABA and glutamate (Stagg et al., 2011b). These results suggest that greater M1 GABA corresponds to an intrinsically more excitable CS pathway, but is also associated with slower RTs. Importantly, no studies have explored the relationship between intrinsic, resting CS excitability and RT.

Here, we set out to examine this question, asking whether individual differences in RT relate to stable underlying differences in CS excitability. We measured RT using a delayed response task in which responses could be prepared in advance of an imperative stimulus. To probe CS excitability, we measured resting motor-evoked potentials (MEPs) elicited with TMS over M1 (Palmer and Ashby, 1992; Rothwell, 1997). Our chosen measures of RT and MEP amplitudes have previously been shown to be highly reliable (Hamsher and Benton, 1977; Carroll et al., 2001; Kamen, 2004; Malcolm et al., 2006; Miller and Ulrich, 2013), a prerequisite for exploring relationships between individual difference measures. Since RT provides a simple, yet important index of the integrity of the nervous system and is influenced by the excitability state of the CS pathway (Day et al., 1989; Pascual-Leone et al., 1994), we predicted that individuals with greater resting excitability should have faster RTs. We also acquired MRS measurements of GABA in M1, and three other control regions, in the same group of individuals allowing us to ask whether relationships between CS excitability, RT, and GABA levels were specific to M1.

\section{Materials and Methods}

Participants. Informed consent was obtained from 24 healthy males $(21.9 \pm$ 2.2 years of age; Edinburgh Handedness Inventory, $70.7 \pm 8.3$, one lefthanded) according to a protocol approved by the University of California, Berkeley Institutional Review Board. Testing was restricted to males to control for between-sex differences and changes in cortical GABA associated with the menstrual cycle (Epperson et al., 2002; O'Gorman et al., 2011). Participants were screened for contraindications associated with TMS and MRI procedures. Data were acquired at four separate sessions that occurred at approximately the same time of day.

TMS and electromyography methods. All participants completed the full TMS protocol during two separate sessions separated by $\sim 2$ weeks (14.7 $\pm 1.4 \mathrm{~d}$ apart). TMS sessions were separated from MRS sessions by $5.0 \pm 0.9 \mathrm{~d}$. This timing between sessions was chosen to assess whether relationships between measurements persisted across days. Single-pulse TMS was administered over the right M1 representation of the left first dorsal interosseous (FDI) muscle using a Magstim 200-2 system with a 7 -cm-diameter figure-of-eight coil. Each session began with a procedure to identify the optimal stimulation location and threshold intensity required to activate the left (FDI) muscle (Fig. 1A). Participants were seated with their hands, palms down, resting on a table, shoulder-width apart.

To identify the optimal scalp location to stimulate right M1, the center of the TMS coil was initially positioned $\sim 2 \mathrm{~cm}$ anterior and $5 \mathrm{~cm}$ to the right of the vertex of the head and oriented $-45^{\circ}$ off of the midline. The TMS intensity was set to $30 \%$ of the maximum stimulator output.
The coil was repositioned gradually, and the stimulation intensity increased until MEPs were detected in electromyography (EMG) recordings from the left FDI. Once the optimal location was identified, the resting motor threshold (rMT) was determined by finding the TMS intensity that elicited 5 of $10 \mathrm{MEPs}$ with peak-to-peak amplitude $>50 \mu \mathrm{V}$. Across individuals, the average rMT as a percentage of maximum stimulator output was $43.8 \pm 6.2 \%$, with values ranging from $37 \%$ to $54 \%$ of maximum stimulator output. The rMT stimulation levels for each individual were highly correlated between the two sessions $(r=0.92, p<$ 0.001 ). rMT is sensitive to factors including individual differences in skull thickness and the geometry of the cortex (Herbsman et al., 2009; Stokes et al., 2013). To hone in on physiological mechanisms, the standard approach is to measure MEP changes as the TMS intensity is increased, relative to rMT (Rossini et al., 2015). This approach defined our primary dependent measure of individual differences in CS excitability, operationalized as the mean amplitude of MEPs elicited at 115\% rMT. This intensity was selected because it consistently elicits MEPs and is well tolerated by participants, thus enabling multiple measurements outside and during task performance.

To determine whether CS excitability changed over the course of the test session, MEPs elicited at 115\% rMT were measured before and after the behavioral task. For each of these two epochs, 20 TMS pulses were administered (40 measurements in total), separated by a randomly jittered interval (4.1-4.7 s, uniform distribution). This number of pulses is sufficient for achieving a reliable measurement of MEP amplitudes within a single session (Chang et al., 2016) and, in terms of measurement reliability, outperforms protocols that include smaller numbers of pulses across a range of TMS intensities with poor internal consistency (Darling et al., 2006). The mean MEP amplitude scores were not significantly different between the two epochs $\left(t_{(19)}=-0.95, p=0.36\right)$ and were highly correlated between the two epochs $(r=0.84, p<0.0001)$. As such, we combined the data from the pretask and post-task epochs in calculating MEP amplitude. Trials in which EMG activity occurred within the $100 \mathrm{~ms}$ preceding TMS were excluded from the analysis. The MEP data presented in the figures are from participants who also provided usable M1 GABA measurements.

Previous studies have failed to observe a relationship between MRS measures of M1 GABA and intracortical inhibition, measured with paired-pulse TMS protocols using interpulse intervals of 2.5 or $3 \mathrm{~ms}$ (Stagg et al., 2011b; Tremblay et al., 2013). Whereas paired-pulse TMS protocols are hypothesized to measure intracortical inhibitory mechanisms, the goal of our study was to explore the relationship between GABA concentrations within M1 and intrinsic corticospinal excitability, not intracortical inhibition. As such, we opted to use a single-pulse TMS protocol.

EMG was recorded from the left and right FDI muscles using bipolar surface electrodes. The analog EMG signal was bandpass filtered (50$2000 \mathrm{~Hz}$; Delsys), digitized at $2000 \mathrm{~Hz}$, and amplified. EMG was used to measure RTs during the behavioral task (Fig. 1B). RT was defined as the first point in which the rectified EMG trace surpassed a threshold of 0.1 $\mathrm{mV}$ and exceeded 1.5 SDs of the mean signal, averaged within each $4 \mathrm{~s}$ recording epoch. All MEP and EMG data were visualized and analyzed using customized scripts in Matlab. MEP peak-to-peak amplitudes were calculated within the interval 19-49 ms after the TMS pulse.

Behavioral task. As our behavioral measure, we used RT in a bimanual delayed response task (Duque et al., 2010; Greenhouse et al., 2015b) in which a cue, appearing $900 \mathrm{~ms}$ before an imperative signal, indicated the hand for the forthcoming response (Fig. 1B). This task allowed us to examine whether our TMS and MRS measures, obtained from one hemisphere, relate to RT in one hand or both hands. We opted to use a task in which the required response was cued at a fixed interval before the imperative to maximize response preparation, minimizing the contribution of selection processes to RT (Rosenbaum, 1980).

Each trial began with the presentation of a fixation stimulus at the center of the display for $200 \mathrm{~ms}$, after which the screen was blanked for a variable interval of 1000-1500 ms (uniform distribution). The cue, a bracket opening to the left or right, was then presented. The direction indicated whether the forthcoming response required a movement of the left or right index finger, and participants were instructed to prepare this 
A
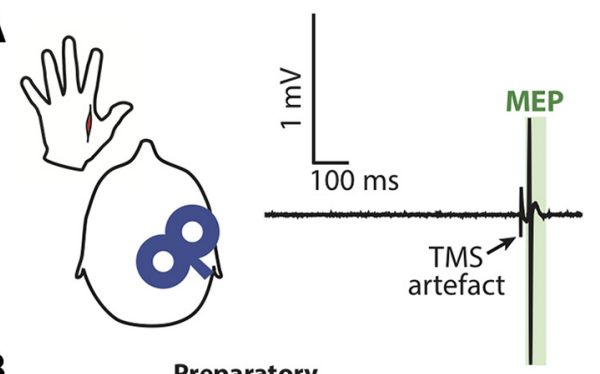

B

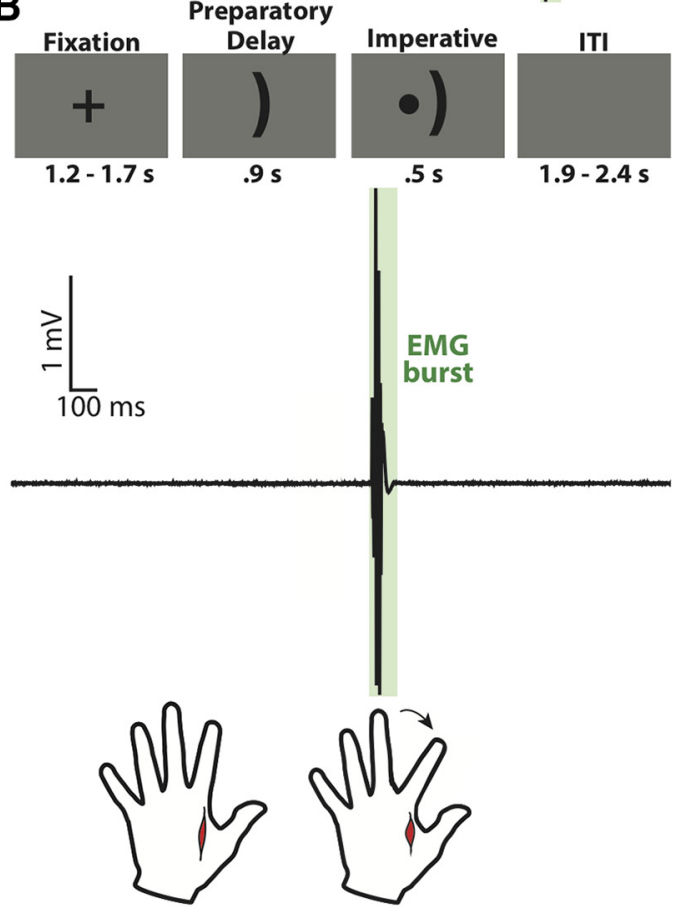

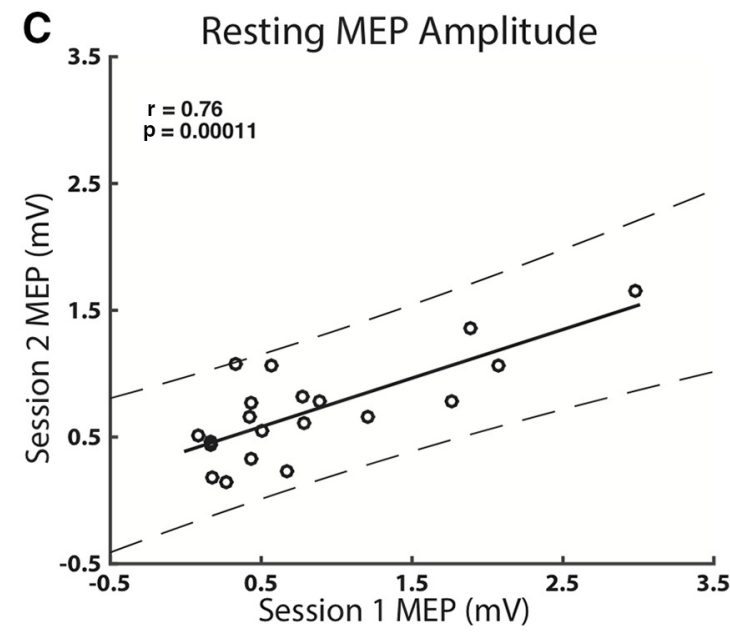

D Choice EMG RT

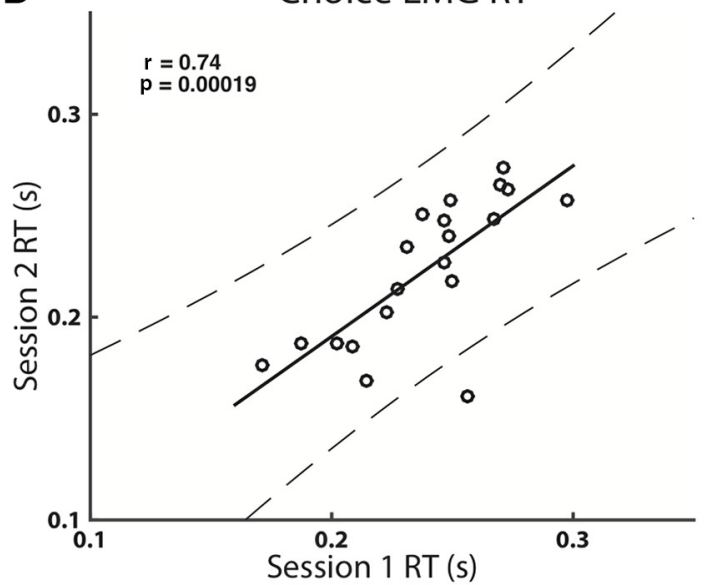

Figure 1. A, TMS was delivered over right M1 to elicit MEPs recorded with EMG from the left FDI hand muscle. $\boldsymbol{B}$, The EMG traces were also used to determine reaction time in the delayed response task. On each trial, an open bracket indicated the hand required for a subsequent response. A circle appeared inside the bracket, signaling that the planned response should be executed. ITI, Intertrial interval. MEP amplitudes at rest (measured with stimulation at $115 \%$ of rMT; $\boldsymbol{C}$ ) and RT were reliable across two sessions $(n=20 ; \boldsymbol{D})$.

response in anticipation of the imperative signal. At the end of a fixed 900 ms preparatory delay period, a circle appeared inside the bracket. This served as the imperative stimulus (500 ms). Participants were instructed to execute the planned response, a lateral abduction of the cued index finger, as quickly as possible. On a subset of trials ( $29.6 \%, 32$ trials total), an X was displayed instead of the imperative stimulus. This indicated that the planned response should be aborted. We included these trials so that participants would not respond in anticipation of the imperative. Each trial was separated by a $1900-2400 \mathrm{~ms}$ blank screen interval, resulting in a total trial duration of $\sim 5 \mathrm{~s}$.

Participants completed a short practice block of 10 trials, followed by two test blocks of 54 trials each (108 trials total). In addition to the MEP measurements taken before and after the task, MEPs were measured during the task (Fig. $1 B$ ) at one of two time points: (1) fixation onset (24 trials) or (2) $800 \mathrm{~ms}$ into the preparatory delay period (56 trials). MEPs measured during the delay period are not discussed here. TMS was not administered on the remaining 28 trials, and these were used to measure $\mathrm{RT}$ in the absence of changes that might result from the TMS pulse (e.g., arousal from the TMS-induced click). Participants were instructed to keep their hands at rest when not responding, to use the cues to prepare their responses, and to respond as quickly and accurately as possible to the imperative stimulus.

A photodiode placed on the screen of the stimulus presentation computer was used to detect the onset of task stimuli. The output of the diode was recorded with the same digital sampler used to record EMG. Participant median EMG RT, relative to imperative stimulus onset, is reported.
Elements of the task design were tailored to address specific questions of interest. The use of a bimanual task allowed us to assess whether relationships between RT and corticospinal excitability were specific to one hand or generalized to both hands. In our previous work, we showed that RTs did not differ between choice and simple variants of the delayed response task (Greenhouse et al., 2015b), suggesting that response competition mechanisms do not influence RT in this task.

The delayed response task reduces sources of task-based variability that would be present in standard RT tasks. The preparatory delay minimizes the contribution of response selection, meaning a larger portion of the RT is composed of response execution processes. Our previous work with this method (Greenhouse et al., 2015b) has shown that RTs in this task are faster than RTs measured without a delay period, consistent with the idea that participants use the preparatory cue to set up responses in advance of the imperative stimulus. The delay task also removes uncertainty about the timing of the imperative, although the inclusion of catch trials does impose a control process.

MRI and MRS methods. In two other sessions ( $15.5 \pm 4.4 \mathrm{~d}$ apart), an MRS protocol was used to obtain estimates of GABA from four voxels (see Fig. $3 A$ ) positioned in primary motor (M1), lateral prefrontal (LPF), premotor (PM), and occipital (OCC) cortex. The LPF, PM, and OCC voxels were included to provide points of comparison for examining the relationship between M1 GABA and CS excitability and/or behavior. In addition to GABA, we performed an exploratory analysis of Glx, a multiplet hypothesized to reflect contributions from glutamate, glutamine, and glutathione. 
The MR imaging procedures were reported by Greenhouse et al. (2016). MR data were collected at the University of California, Berkeley Brain Imaging Center on a 3 tesla Siemens TIM/Trio scanner using a 32-channel head coil. Two T1-weighted anatomical scans (sagittal MPRAGE; TR/TE, 1900/ $2.52 \mathrm{~ms} ; 900 \mathrm{~ms}$ TI; flip angle, $9^{\circ}$; FOV, $250 \times 176 ; 1 \mathrm{~mm}^{3}$ voxel size; acceleration factor of 2) were acquired and resliced into coronal and axial planes to assist with positioning of the MRS voxels. Eight Mescher-Garwood point-resolved spectroscopy (MEGA-PRESS; (Mescher et al., 1996, 1998) scans (160 averages per scan; TR/TE, 1500/68 ms; 1.9 and 7.5 ppm On- and Off-resonance edit pulse frequencies; $45 \mathrm{~Hz}$ edit pulse bandwidth; $-1.7 \mathrm{ppm}$ delta frequency (specific to Siemens); $50 \mathrm{~Hz}$ water suppression; TA, $8.4 \mathrm{~min}$ ) were acquired, two scans for each of the M1, LPF, PM, and OCC voxels. MEGA-PRESS measurements alternated between On- and Off-resonance editing pulses. Because of our interest in individual differences, the scan order was the same for all participants to minimize participant-by-order interactions (Friedman et al., 2008). The order was T1-weighted image, two LPF MRS scans, two M1 MRS scans, T1-weighted image, two PM MRS scans, and two OCC MRS scans. Because of time constraints in the scanner, we were able to obtain OCC spectra in only 15 participants.

Gradient orders, local shims, and anatomical positioning (see Fig. $3 A$ ) were optimized for each region. The $\mathrm{M} 1$ voxel $(30 \times 30 \times 30 \mathrm{~mm})$ was centered over the "hand knob" of the right precentral gyrus, with one face parallel to the cortical surface and the long axis parallel to the longitudinal fissure. The LPF voxel $(25 \times 40 \times 25 \mathrm{~mm})$ was centered over the right inferior frontal junction, with one face parallel to the cortical surface and the longest axis extending along the anteroposterior axis. The PM voxel $(25 \times 40 \times 25 \mathrm{~mm})$ was centered over right medial premotor cortex, with the posterior face aligned to the precentral sulcus and a lateral face aligned to the longitudinal fissure. The superior face of the PM voxel was positioned parallel to the cortical surface. This voxel included portions of SMA and dorsal premotor cortex. The OCC voxel was centered bilaterally over the calcarine sulcus, extending equally into the left and right hemispheres. The ventral surface of the OCC voxel was parallel to the straight sinus. In addition to the anatomical landmarks, screen captures of voxel placement were taken at the first MRI session and used to guide placement of the voxel at the second session.

MRS data were analyzed using customized routines in Matlab. Every 10 averages, from the total of 160 averages acquired within each scan, were averaged together, yielding 16 On-resonance and 16 Off-resonance averaged spectra per scan. Spectra were zero-filled from 1024 to 4096 data points, apodized with a $4 \mathrm{~Hz}$ Gaussian function, and manually phase corrected and aligned to creatine (Cr; Evans et al., 2013; Near et al., 2015). A combined automated and manual routine was used to identify spectra containing large numbers of extreme values that were excluded from further analysis (Near et al., 2013). The mean percent averages removed (of 64 averages total) was $0.5 \pm 0.4 \%$ for the LPF, $0.4 \pm 0.3 \%$ for the M1, $0.3 \pm 0.2 \%$ for the PM, and none for the OCC voxel.

Metabolite estimation was performed using an established method (Yoon et al., 2010; Maddock et al., 2016). GABA + signal was calculated from the signal between 2.85 and $3.15 \mathrm{ppm}$ in the difference spectra (see Fig. $3 A$ ), and $\mathrm{Cr}$ signal was calculated from the signal between 2.93 and $3.10 \mathrm{ppm}$ in the summed On- and Off-resonance spectra. In addition to the GABA peak at $3.00 \mathrm{ppm}$, we estimated the Glx peak at $3.75 \mathrm{ppm}$ in the difference spectra, hypothesized to reflect contributions from glutamine, glutamate, and glutathione. However, we consider our Glx analysis exploratory for two reasons. First, the imaging sequence was tailored to measure GABA (TE, $68 \mathrm{~ms}$; On-resonance editing frequency, $1.9 \mathrm{ppm}$ ). Second, glutamate, glutamine, and glutathione contributions cannot be separated using our protocol. We include Glx here primarily as a point of comparison for GABA because the measurement was acquired at the same time and with the same MEGA-PRESS pulse sequence.

The ratios of total GABA and total Glx to total Cr signal (GABA/Cr and $\mathrm{Glx} / \mathrm{Cr}$, respectively) were calculated for each scan. By using the ratios relative to the simultaneously acquired $\mathrm{Cr}$ reference, we control for multiple variables in the MR environment that can change between scans (Mullins et al., 2014). As is the case for all MRS measurements that include a reference, any effects can be attributed to variation in the reference; in this case, Cr. Data included in the final analyses comprised spectra from two scans acquired within each of the two sessions (640 On transients and 640 Off transients in total), after screening for artifacts. Participants were only included in the analysis if all four scans yielded artifact-free data. This resulted in a final sample size of 20 for the primary analyses (four eliminated because of incomplete data sets for M1 and LPF). Analyses involving the OCC spectra are based on a sample size of only 15 individuals, the number who were able to complete the four scans of this voxel because of time constraints with the scanner, and results from the OCC spectra should be interpreted with caution. MRS measurement reliability was evaluated by comparing across the two sessions.

\section{Results}

\section{Resting MEP amplitudes correlate with RT}

MEP amplitudes, measured at 115\% rMT before and after the task, were positively correlated across the two sessions $(r=0.76$, $p<0.001$; Fig. $1 C$ ), and a paired $t$ test showed these MEP amplitudes were not significantly different between sessions $\left(_{(19)}=\right.$ $1.00, p=0.33)$. Similarly, individual differences in RT were positively correlated across sessions $(r=0.74, p<0.001$; Fig. $1 D)$. RT was $239 \pm 31 \mathrm{~ms}$ at the first session and $223 \pm 36 \mathrm{~ms}$ at the second session, and, albeit only a $16 \mathrm{~ms}$ difference, this was statistically significant $\left(t_{(19)}=2.86, p=0.01\right)$. The effect was similar for both the left $\left(t_{(19)}=2.13, p<0.05\right)$ and right $\left(t_{(19)}=2.14, p<0.05\right)$ hands. To test the hypothesis that individual differences in intrinsic CS excitability correlate with the speed of initiating a planned motor response, we compared these two measures (averaging across sessions). We observed a significant negative relationship $(r=-0.46, p<0.05)$ : individuals with more excitable CS pathways at rest were faster to initiate planned responses during the delayed response task. This relationship was most pronounced for left index finger RTs, responses that engaged the FDI muscle from which MEPs were measured ( $r=-0.5, p<0.05$; Fig. $2 A)$. Although a similar pattern was observed for right index finger RTs, the correlation was not significant $(r=-0.36, p=0.12$; Fig. 2A).

This result was also observed using a separately acquired measure of CS excitability, MEPs (115\% rMT) taken during the intertrial interval of the delayed response task (i.e., task baseline). These task baseline MEP amplitude measurements were not significantly different from MEPs measured before and after the task $\left(t_{(19)}=1.02, p=0.32\right)$ and were not significantly different between sessions $\left(t_{(19)}=0.70, p=0.49\right)$. Similar to MEPs measured outside the task, MEP amplitudes measured at task baseline were also negatively correlated with RT (both hands: $r=-0.52, p<$ 0.05 ; left hand: $r=-0.52, p<0.05$; right hand: $r=-0.45$, $p<0.05$; Fig. $2 B$ ). However, we are cautious in drawing inferences from the MEPs measured during the task baseline since they could be influenced by general factors that also impact RT. Nonetheless, it is noteworthy that we observed the same relationship between RT and CS excitability, regardless of whether the latter was measured outside or within the behavioral task context.

\section{M1 GABA content correlates with resting MEP amplitudes but not RT}

As reported by Greenhouse et al. (2016), M1 GABA/Cr measurements (Fig. $3 A$ ) were correlated across sessions $(r=0.46, p<$ $0.05)$, and the same was true for the other three measurement voxels (LPF: $r=0.55, p=0.01$; PM: $r=0.57, p<0.01$; OCC: $r=$ $0.66, p<0.01)$. GABA/Cr measurements were not significantly different between sessions for any of the voxels (all $p$ values $>0.47$ ). In line with a previous report (Stagg et al., 2011b), we observed a positive correlation between our measure of CS excitability (MEP amplitudes) and M1 GABA/Cr estimates. This correlation was observed for MEPs measured outside the task ( $r=$ $0.48, p<0.05$; Fig. $3 B$ ) and those measured during the intertrial 

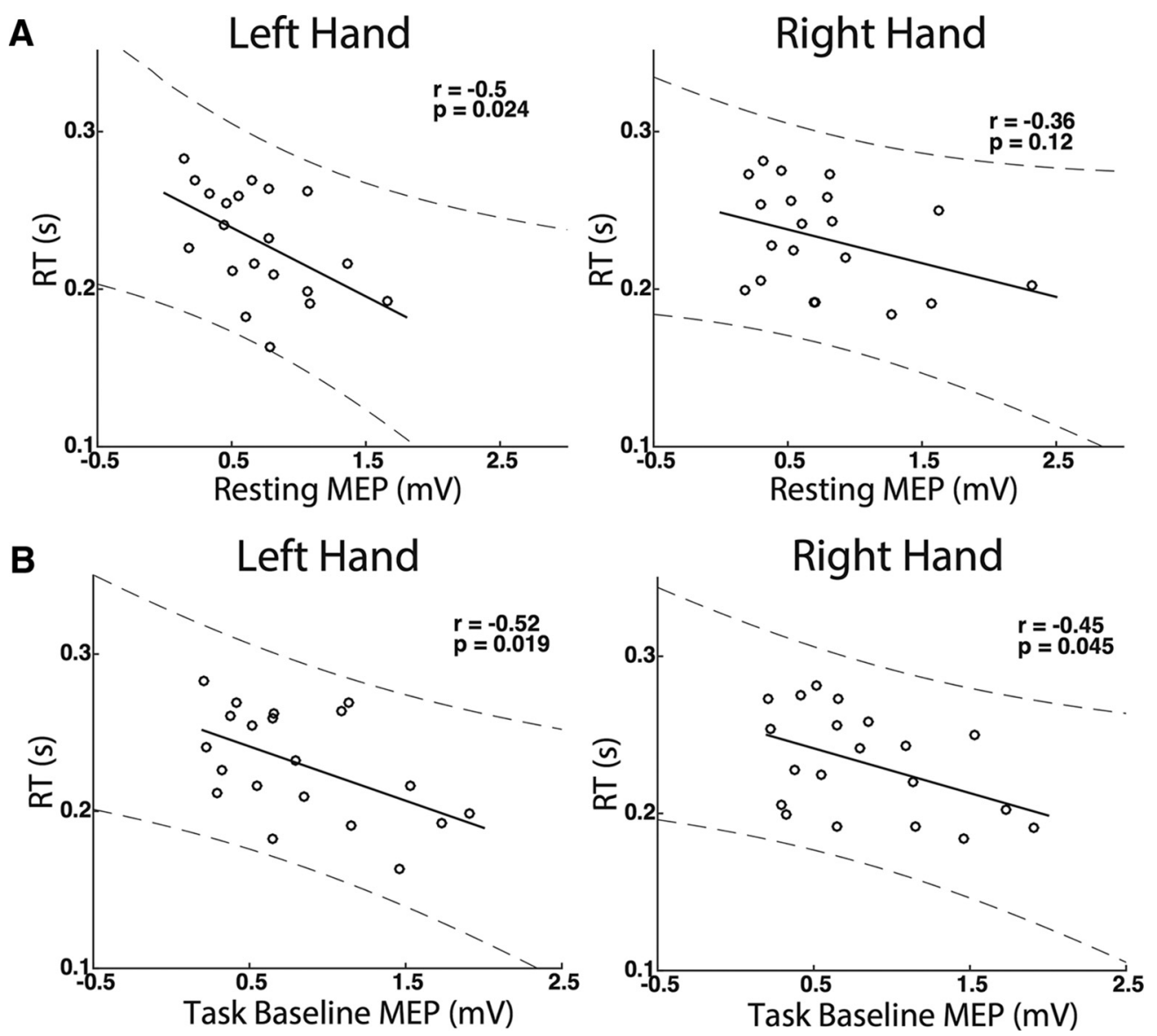

Figure 2. Intrinsic corticospinal excitability was negatively correlated with RT. A, MEP amplitudes measured at rest negatively correlated with left-hand RT. A nonsignificant but similar pattern was observed for right-hand RTs. B, Separate measurements of MEP amplitudes taken during the task intertrial interval were negatively correlated with both left- and right-hand RTs.

interval of the delayed response task $(r=0.49, p<0.05$; Fig. $3 C)$. Consistent with Stagg et al. (2011b), individuals with higher GABA/Cr content in M1 exhibited larger MEP amplitudes when probed at rest.

Interestingly, the relationships were specific to M1. The other three MRS voxels (LPF, PM, and OCC) exhibited no significant relationships between GABA and CS excitability (MEP amplitudes at $115 \%$ rMT; Fig. $3 B, C$ ). Fisher's $r$-to- $z$ transformations showed that the correlation between task baseline MEP amplitudes and GABA/Cr was significantly greater for M1 than PM $(z=1.98, p<0.05)$, with the comparison between M1 and LPF approaching significance $(z=1.88, p=0.06)$. The comparison of the M1 and OCC correlations was not significant $(z=0.77, p=$ 0.44 ), although the sample size was small for the OCC voxel.

rMT exhibited a trend-level negative correlation with GABA/ Cr estimates in M1 $(r=-0.41, p=0.07)$ : lower TMS intensities were needed to elicit MEPs from individuals with higher levels of GABA/Cr in M1 (Fig. 4). This pattern was not observed in the other MRS voxels. Notably, rMT did not correlate with RT, averaged across both hands or for either hand alone (all $p$ values $>0.82$ ).

Despite the observed relationships between resting MEP amplitudes and RT, and between resting MEP amplitudes and GABA/Cr in M1, we did not observe a significant correlation between $\mathrm{RT}$ and GABA/Cr in any of the four MRS voxels (all $p$ values $>0.17$; Fig. 5 ). This pattern suggests that, although MEP amplitudes predict both individual differences in RT and in M1 GABA content, these relationships may reflect separate sources of the variance that underlie individual differences in CS excitability.

Notably, the relationships were specific to GABA. The Glx/Cr estimate for any of the four MRS voxels did not correlate with the MEP or RT measurements (all $r$ values $<0.38$, all $p$ values $>0.17$; Fig. 6). When controlling for $\mathrm{Glx} / \mathrm{Cr}$ using a partial correlation analysis, the correlation between M1 GABA/Cr and MEP amplitudes measured at rest remained significant $(r=0.5, p<0.05)$, and the same was true for the correlation between M1 GABA/Cr and MEP amplitudes measured at task baseline $(r=0.45, p=$ $0.05)$. These partial correlations indicate that Glx did not account for the relationship between GABA and our measures of resting corticomotor excitability.

\section{Discussion}

We observed that individuals with more excitable CS pathways at rest exhibited faster RTs and higher concentrations of GABA in M1. Importantly, the relationships between the MRS and TMS measures were specific to M1; there were no relationships between GABA measured within LPF, PM, or OCC cortex and our TMS or RT measures. Moreover, intrinsic excitability was not correlated with Glx measured simultaneously with GABA. Collectively, these results suggest that individuals with greater intrinsic CS excitability are quicker to execute planned motor responses and maintain higher basal levels of GABA within M1. 

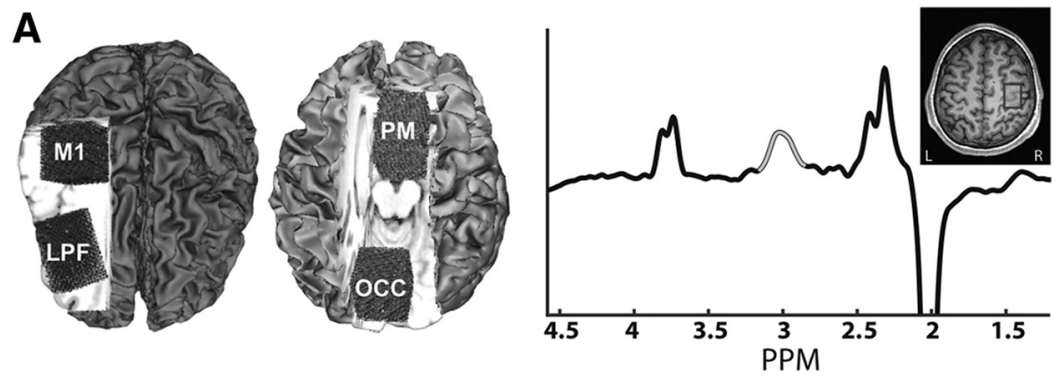

B
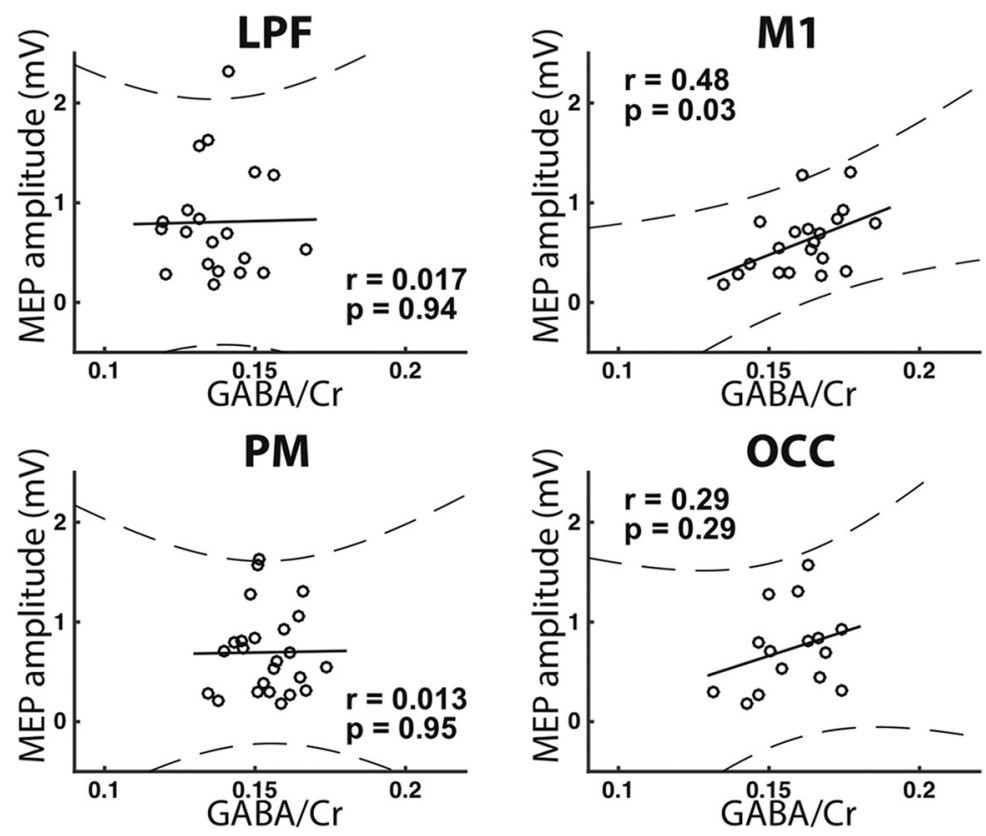

C
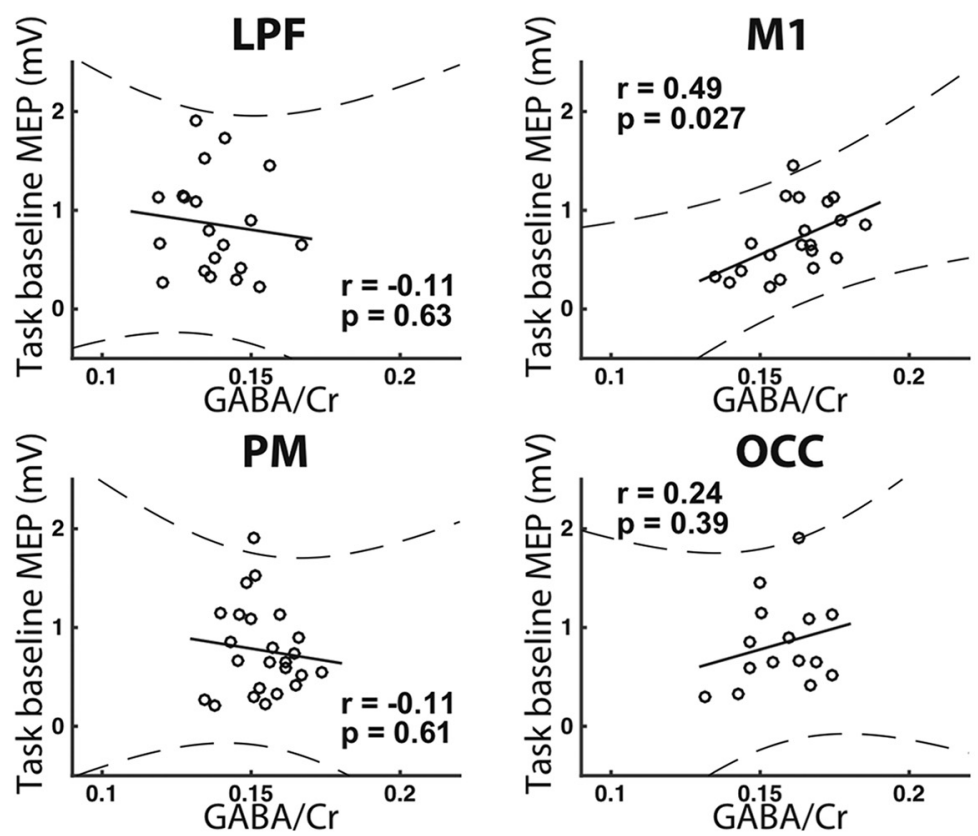

Figure 3. $A, G A B A$ measurements were taken in four voxels positioned in LPF, M1, PM, and OCC cortex. The M1 voxel was centered over the hand knob of right M1 (inset), and the GABA peak (lighter trace, $\sim 3$ ppm) was estimated from the difference spectrum (black trace, example from a single scan). GABA content in right $M 1$, represented as a ratio relative to creatine, was positively correlated with MEP amplitudes measured before and after the task $(\boldsymbol{B})$ and during the intertrial interval of the delayed response task $(\boldsymbol{C})$. The relationship was not present for GABA measured in the three other voxels.
Intrinsic corticospinal excitability and reaction time

The negative correlation between CS excitability and RT is consistent with the hypothesis that these measures reflect common intrinsic properties of the motor system. We assume that RTs and MEPs are composite measures, consisting of transient, staterelated changes in cortical dynamics that occur on top of relatively invariant, individual differences. Previous work with TMS has clearly established that MEPs and, to some degree, RT, are highly sensitive to transient changes in motor system excitability (Starr et al., 1988; Leocani et al., 2000; Greenhouse et al., 2015b; Michaels et al., 2015; Hammer et al., 2016). Here, we demonstrate that RT and MEP measurements exhibit stable individual differences. Since the MEPs were measured outside a task context, it is unlikely that transient changes in excitability accounted for the correlation between these measures. Instead, the correlation indicates that stable, trait-based factors contribute to task-independent variation in the excitability state of the CS pathway.

The relationship between CS excitability and RT could arise at multiple levels within the motor pathway. The baseline level of cortical activity, the conductivity of efferent projections to the spinal cord, the excitability of upper and lower motor neurons, and the overall milieu of the neuromuscular junction could contribute to individual differences. Whereas TMS may affect processes upstream from the CS pathway that influence MEP amplitudes, the MEP latency relative to the TMS pulse, i.e., the central motor conduction time, in the targeted FDI muscle in this study was estimated to be $24.1 \pm 0.1 \mathrm{~ms}$. This latency is only sufficient for a volley of activity to travel trans-synaptically within the cortex to cortical pyramidal cells, and onward to a pool of motoneurons in the spinal cord to activate the muscle. Transmission across additional synapses would result in longer latencies. Furthermore, paired-pulse TMS protocols imply that additional manipulations are necessary to recruit mechanisms that exert modulatory influences over CS excitability (Valls-Solé et al., 1992; Kujirai et al., 1993). This is consistent with the idea that the MEP resulting from a single suprathreshold TMS pulse is a useful index of the state of the CS pathway. However, the precise factors that contribute to the MEP are not fully understood (Di Lazzaro and Rothwell, 2014; Bestmann and Krakauer, 2015), and we can only speculate as to which factors explain the current findings. 

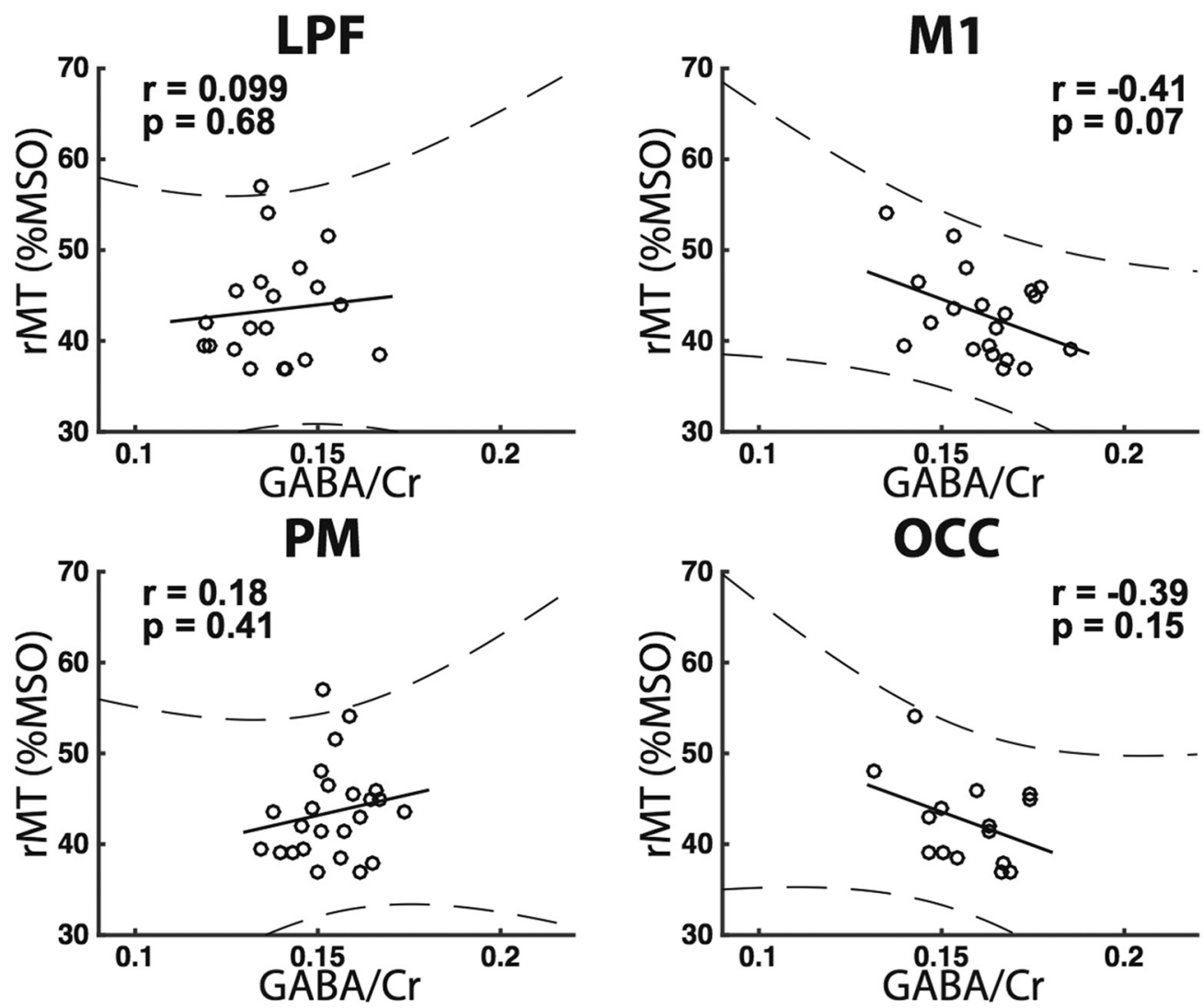

Figure 4. A trend-level negative correlation was observed between GABA content in M1 and rMT, the minimum stimulation intensity needed to reliably elicit motor-evoked potentials (represented as a percentage of maximum stimulator output; \%MSO). The relationship was not present for GABA measured in the three other voxels.
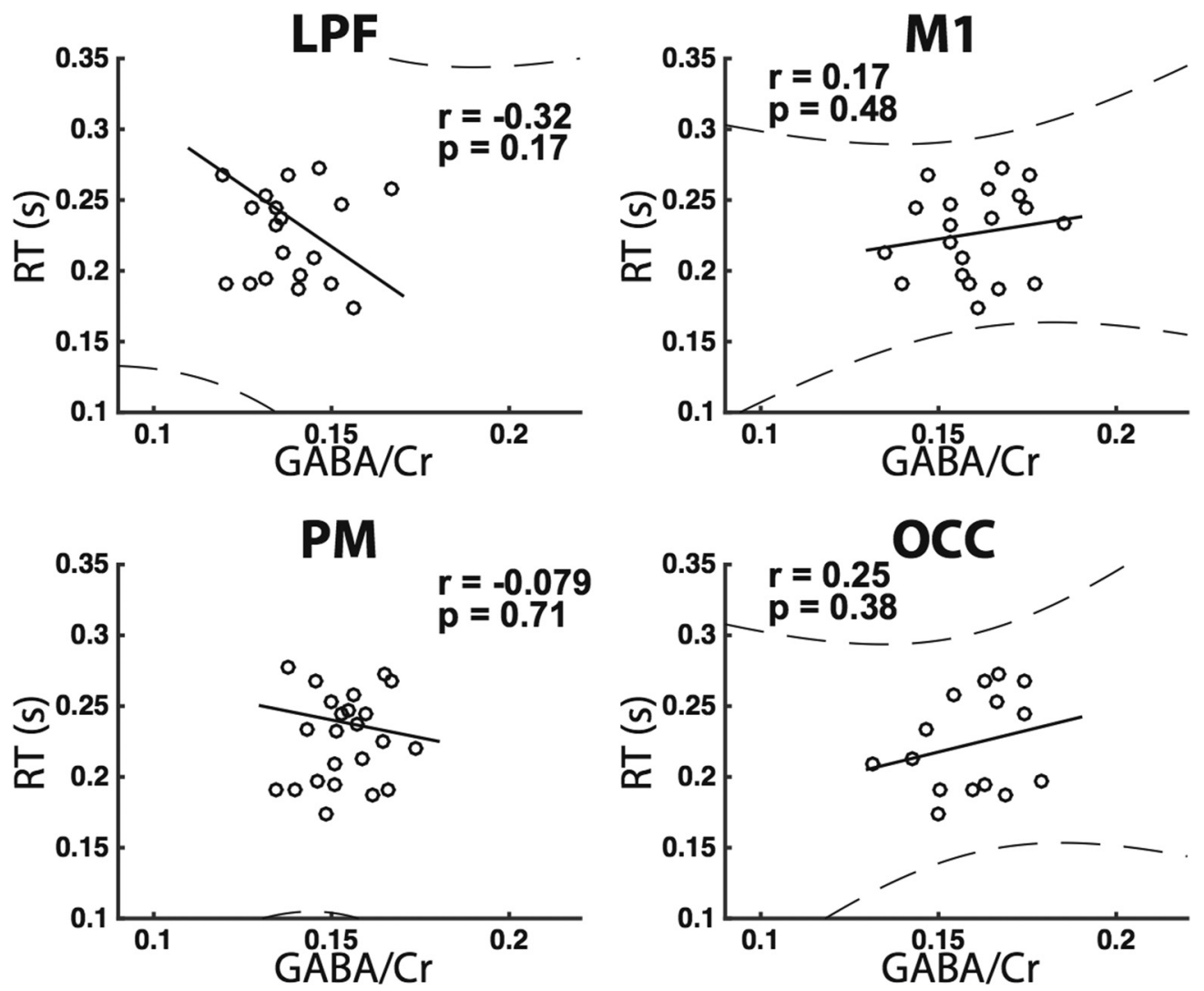

Figure 5. There was no correlation between RT on the delayed response task and GABA concentration measured in any of the four MRS voxels. 
A
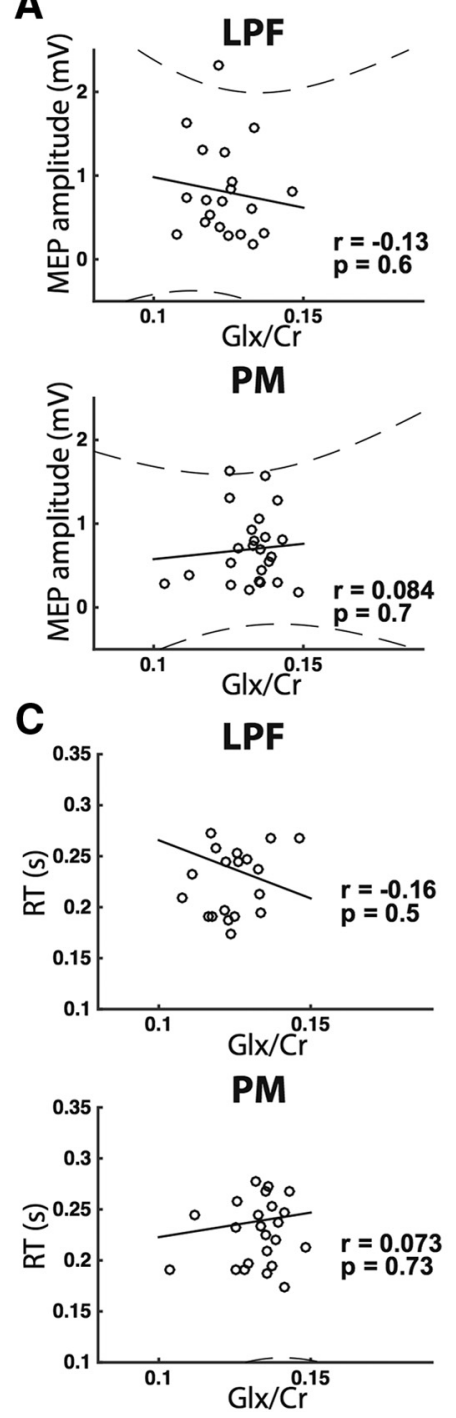
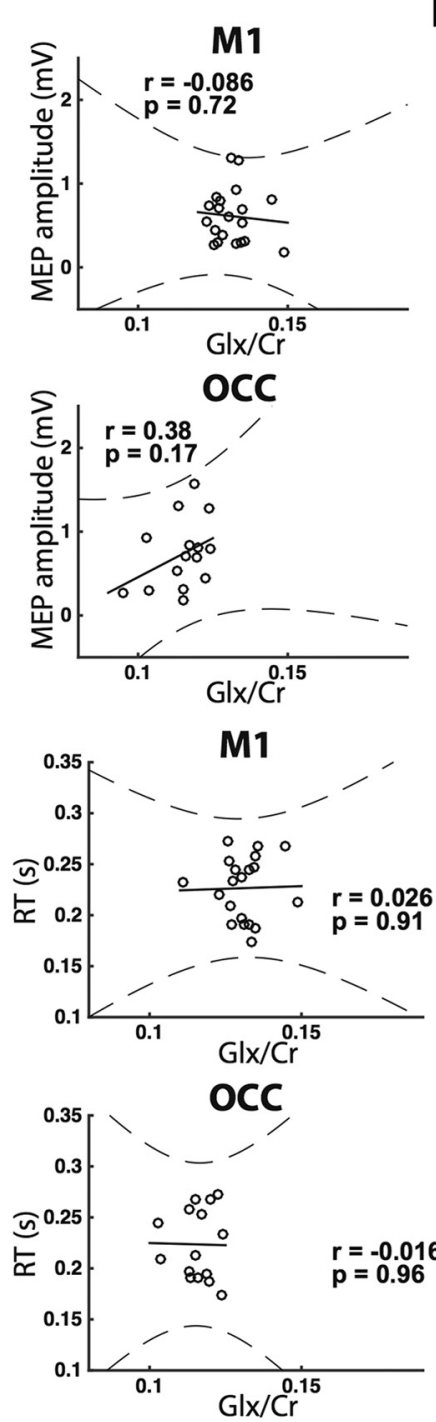

B
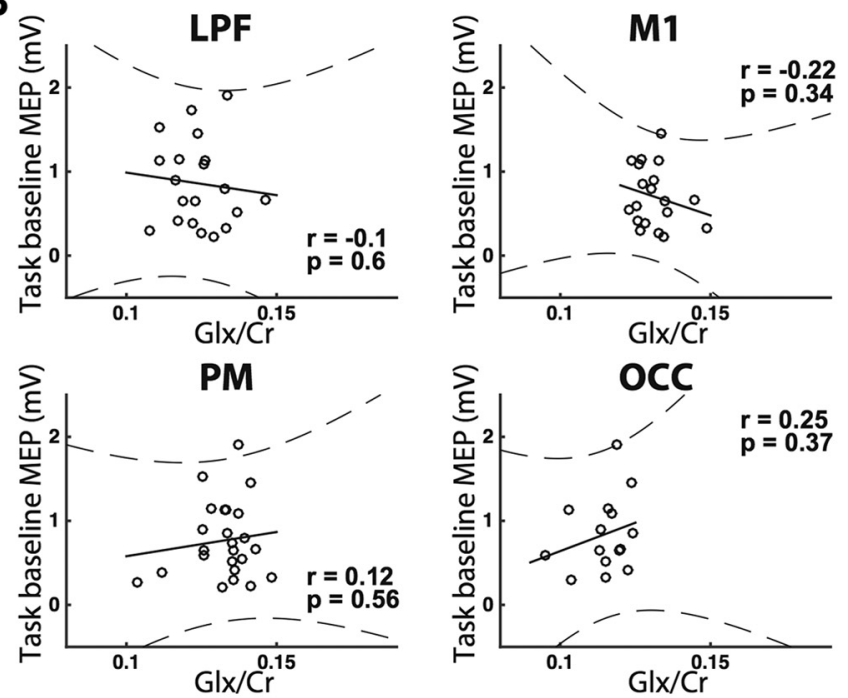

Figure 6. Glx measured in any of the four voxels did not correlate with MEP amplitudes measured at rest before and after the task $(\boldsymbol{A})$ or during the intertrial interval task baseline $(\boldsymbol{B})$. $\boldsymbol{C}$, RT did not correlate with GIx in any of the four voxels.

Although the MEP measure provides a useful index of CS excitability, it may also be sensitive to individual differences that generalize to other neural pathways. Successful performance of the delayed response task used here depends on stimulus detection, stimulus discrimination, response preparation, and response implementation; all these processes contribute to RT. Studies have reported that individual differences in anatomical measures believed to reflect neural pathway integrity are relatively widespread in the brain (Penke et al., 2010; Johnson et al., 2015). Furthermore, widespread developmental changes in white matter integrity, including within the CS tract, predict decreases in RT variability (Tamnes et al., 2012). It is possible that MEPs, a probe on CS integrity (Stinear et al., 2007), predict the integrity of other neural pathways involved in processes that precede response execution. Individual differences in both RT and MEP amplitude may reflect properties that generalize to neural pathways beyond the CS tract.

The use of only one TMS intensity (115\% rMT) is a limitation of our study. An alternative would be to measure the slope of the input-output (I/O) recruitment curve. This measure was reported in a previous study (Stagg et al., 2011b), and, consistent with our results, a correlation was observed between the recruit- ment curve slope and M1 GABA. Our data show a similar relationship when corticospinal excitability is measured at a single TMS intensity. We focused on 115\% rMT because MEPs measured at this intensity lie within the rising phase of the $\mathrm{I} / \mathrm{O}$ curve (Rossini et al., 2015), and the range of $110 \%$ and $120 \%$ rMT is commonly used to assess both resting and state-dependent changes in corticomotor excitability (Duque et al., 2010, 2012; Kroeger et al., 2010; Cai et al., 2011; Stagg et al., 2011b; Feurra et al., 2013; Labruna et al., 2014; Schulz et al., 2014; Lebon et al., 2016). Moreover, the overall protocol was quite extensive, mandating that we make some decisions to keep the session duration reasonable.

\section{Functional significance of intrinsic cortical GABA content}

GABA content in M1 positively correlated with CS excitability (see also Stagg et al., 2011b). At first blush, the direction of this relationship seems counterintuitive: a priori, one might expect high levels of an inhibitory neurotransmitter to reduce excitability. We speculate that intrinsic concentrations of GABA in M1 provide a homeostatic mechanism, given variation in CS excitability. By this hypothesis, greater GABA content within M1 
could offset a more excitable CS pathway. Conversely, a more excitable motor projection pathway may require greater capacity for inhibition, and thus demand a larger reserve from which inhibitory neurotransmitter can be replenished. This reservoir of neurotransmitter may be particularly important for supporting the functions of the extensive and diverse population of cortical inhibitory interneurons that exhibit relatively high firing rates (Gupta et al., 2000). More work is needed to test this hypothesis and to establish a mechanistic framework.

Whereas many computational models of cortical networks suggest that the relative proportion of excitatory to inhibitory connections determines the current state of excitability (van Vreeswijk and Sompolinsky, 1996; Tsodyks et al., 1997; Hennequin et al., 2014), neurotransmitter availability is also likely to be a key factor. MRS provides an estimate of the overall tissue content of GABA within the measurement region. By far, the largest fraction of cortical GABA is localized to the cytoplasm of GABAergic interneurons, with smaller amounts found in synaptic vesicles and in the synaptic zone (Curtis and Johnston, 1974; Waagepetersen et al., 2003; Waagepetersen and Sonnewald, 2007). Higher cytoplasmic concentrations of neurotransmitters are associated with more complete vesicular filling and larger quantal size (Edwards, 2007; Bartoletti and Thoreson, 2011). Thus, our MRS measures are best viewed as a proxy for the overall availability of GABA for neurotransmission.

GABAergic mechanisms are implicated in a wide range of functions (Owens and Kriegstein, 2002), including the tuning of receptive fields (Hubel and Wiesel, 1962; Ben-Yishai et al., 1995), the shaping of columnar architecture in visual cortex (Hensch and Stryker, 2004), and the gating of long-term potentiation (Ehrlich et al., 2009). Similar to what we observed here between GABA and CS excitability, these other processes may also be sensitive to GABA availability. Interestingly, our findings were regionally specific to $\mathrm{M} 1$, similar to other reports relating GABA concentrations to physiological or behavioral measures (Grachev and Apkarian, 2000; Grachev et al., 2001; Boy et al., 2011; Dharmadhikari et al., 2015; Durst et al., 2015; Heba et al., 2016; Mikkelsen et al., 2016). GABA concentration in the three other cortical regions measured showed no relationship with CS excitability. This regional specificity is in accord with our previous work showing that individual differences in GABA concentration are reliable within a voxel but exhibit, at best, a modest correlation between regions (Greenhouse et al., 2016).

Given the observed relationship between CS excitability and RT, and that between CS excitability and GABA, we might expect that higher concentrations of M1 GABA would also be associated with faster RTs. However, this relationship was not observed. Indeed, contrary to this prediction, Stagg et al. (2011a) reported that individuals with higher M1 GABA content demonstrated slower RTs. However, in that study, RT was measured using a motor sequence task with a small sample of participants. That task did not separate response selection and preparation from response execution processes. Unlike this previous study, we measured RT using EMG onset in a delayed response task framework, one that allowed participants to prepare the planned response for rapid execution. Consequently, our RT measures were considerably faster than those observed by Stagg et al. (2011a). These task differences may explain why M1 GABA and RT were not correlated in the current study.

\section{Conclusions}

We identified stable individual differences in measures of motor system physiology, neurotransmitter concentrations, and behav- ior and observed two interesting relationships between these variables. First, individuals with higher resting CS excitability were faster at initiating a planned response. Second, these individuals had higher levels of GABA within M1. GABA levels in other cortical regions did not exhibit any relationship to CS excitability. We offer the novel theoretical interpretation that resting motor system excitability is one factor contributing to individual variation in behavioral response time and that higher basal levels of GABA within M1 compensate for a more excitable CS pathway.

Our results have important clinical implications. TMS measures of resting motor system excitability are abnormal in patients with neurological disorders (Rossini and Rossi, 1998; Pascual-Leone, 2003) and track symptom severity. For example, MEP amplitudes, measured at rest over a broad range of stimulation intensities, are increased in Parkinson's disease (Kandler et al., 1990; Tremblay and Tremblay, 2002; Lefaucheur, 2005). Moreover, the presence of MEPs predicts recovery after stroke (Escudero et al., 1998; Stinear et al., 2007), and the balance of excitatory and inhibitory MEP measures is disrupted after head trauma (Chistyakov et al., 2001). The study of MEP amplitudes in healthy individuals may provide insight into the affected mechanisms and improve our understanding of the inhibition-excitation balance. There may be a limit to the putative homeostatic role for GABA within M1, and once the demand for GABA exceeds its intrinsic capacity, unwanted movements may be expressed. Changes in basal GABA may precede the manifestation of symptoms and may have clinical utility for early detection of disease.

\section{References}

Bartoletti TM, Thoreson WB (2011) Quantal amplitude at the cone ribbon synapse can be adjusted by changes in cytosolic glutamate. Mol Vis 17: 920-931. Medline

Ben-Yishai R, Bar-Or RL, Sompolinsky H (1995) Theory of orientation tuning in visual cortex. Proc Natl Acad Sci U S A 92:3844-3848. CrossRef Medline

Bestmann S, Krakauer JW (2015) The uses and interpretations of the motor-evoked potential for understanding behaviour. Exp Brain Res 233: 679-689. CrossRef Medline

Boy F, Evans CJ, Edden RA, Lawrence AD, Singh KD, Husain M, Sumner P (2011) Dorsolateral prefrontal $\gamma$-aminobutyric acid in men predicts individual differences in rash impulsivity. Biol Psychiatry 70:866-872. CrossRef Medline

Cai W, Oldenkamp CL, Aron AR (2011) A proactive mechanism for selective suppression of response tendencies. J Neurosci 31:5965-5969. CrossRef Medline

Carroll TJ, Riek S, Carson RG (2001) Reliability of the input-output properties of the cortico-spinal pathway obtained from transcranial magnetic and electrical stimulation. J Neurosci Methods 112:193-202. CrossRef Medline

Chang WH, Fried PJ, Saxena S, Jannati A, Gomes-Osman J, Kim Y-H, Pascual-Leone A (2016) Optimal number of pulses as outcome measures of neuronavigated transcranial magnetic stimulation. Clin Neurophysiol 127:2892-2897. CrossRef Medline

Chistyakov AV, Soustiel JF, Hafner H, Trubnik M, Levy G, Feinsod M (2001) Excitatory and inhibitory corticospinal responses to transcranial magnetic stimulation in patients with minor to moderate head injury. J Neurol Neurosurg Psychiatry 70:580-587. CrossRef Medline

Curtis DR, Johnston GA (1974) Amino acid transmitters in the mammalian central nervous system. Ergeb Physiol 69:97-188. Medline

Darling WG, Wolf SL, Butler AJ (2006) Variability of motor potentials evoked by transcranial magnetic stimulation depends on muscle activation. Exp Brain Res 174:376-385. CrossRef Medline

Day BL, Rothwell JC, Thompson PD, Maertens de Noordhout A, Nakashima K, Shannon K, Marsden CD (1989) Delay in the execution of voluntary movement by electrical or magnetic brain stimulation in intact man. 
Evidence for the storage of motor programs in the brain. Brain 112:649663. Medline

Dharmadhikari S, Ma R, Yeh CL, Stock AK, Snyder S, Zauber SE, Dydak U, Beste C (2015) Striatal and thalamic GABA level concentrations play differential roles for the modulation of response selection processes by proprioceptive information. Neuroimage 120:36-42. CrossRef Medline

Di Lazzaro V, Rothwell JC (2014) Corticospinal activity evoked and modulated by non-invasive stimulation of the intact human motor cortex. J Physiol 592:4115-4128. CrossRef

Duque J, Ivry RB (2009) Role of corticospinal suppression during motor preparation. Cereb Cortex 19:2013-2024. CrossRef Medline

Duque J, Lew D, Mazzocchio R, Olivier E, Ivry RB (2010) Evidence for two concurrent inhibitory mechanisms during response preparation. J Neurosci 30:3793-3802. CrossRef Medline

Duque J, Labruna L, Verset S, Olivier E, Ivry RB (2012) Dissociating the role of prefrontal and premotor cortices in controlling inhibitory mechanisms during motor preparation. J Neurosci 32:806-816. CrossRef Medline

Durst CR, Michael N, Tustison NJ, Patrie JT, Raghavan P, Wintermark M, Sendhil Velan S (2015) Noninvasive evaluation of the regional variations of GABA using magnetic resonance spectroscopy at 3 tesla. Magn Reson Imaging 33:611-617. CrossRef Medline

Edwards RH (2007) The neurotransmitter cycle and quantal size. Neuron 55:835-858. CrossRef Medline

Ehrlich I, Humeau Y, Grenier F, Ciocchi S, Herry C, Lüthi A (2009) Amygdala inhibitory circuits and the control of fear memory. Neuron 62:757-771. CrossRef Medline

Epperson CN, Haga K, Mason GF, Sellers E, Gueorguieva R, Zhang W, Weiss E, Rothman DL, Krystal JH (2002) Cortical gamma-aminobutyric acid levels across the menstrual cycle in healthy women and those with premenstrual dysphoric disorder: a proton magnetic resonance spectroscopy study. Arch Gen Psychiatry 59:851-858. CrossRef Medline

Escudero JV, Sancho J, Bautista D, Escudero M, López-Trigo J (1998) Prognostic value of motor evoked potential obtained by transcranial magnetic brain stimulation in motor function recovery in patients with acute ischemic stroke. Stroke 29:1854-1859. CrossRef Medline

Evans CJ, Puts NA, Robson SE, Boy F, McGonigle DJ, Sumner P, Singh KD, Edden RA (2013) Subtraction artifacts and frequency (mis-)alignment in J-difference GABA editing. J Magn Reson Imaging 38:970-975. CrossRef Medline

Feurra M, Pasqualetti P, Bianco G, Santarnecchi E, Rossi A, Rossi S (2013) State-dependent effects of transcranial oscillatory currents on the motor system: what you think matters. J Neurosci 33:17483-17489. CrossRef Medline

Fox MD, Snyder AZ, Vincent JL, Raichle ME (2007) Intrinsic fluctuations within cortical systems account for intertrial variability in human behavior. Neuron 56:171-184. CrossRef Medline

Friedman NP, Miyake A, Young SE, Defries JC, Corley RP, Hewitt JK (2008) Individual differences in executive functions are almost entirely genetic in origin. J Exp Psychol Gen 137:201-225. CrossRef Medline

Grachev ID, Apkarian AV (2000) Chemical heterogeneity of the living human brain: a proton MR spectroscopy study on the effects of sex, age, and brain region. Neuroimage 11:554-563. CrossRef Medline

Grachev ID, Swarnkar A, Szeverenyi NM, Ramachandran TS, Apkarian AV (2001) Aging alters the multichemical networking profile of the human brain: an in vivo (1)H-MRS study of young versus middle-aged subjects. J Neurochem 77:292-303. CrossRef Medline

Greenhouse I, Saks D, Hoang T, Ivry RB (2015a) Inhibition during response preparation is sensitive to response complexity. J Neurophysiol 113:27922800. CrossRef Medline

Greenhouse I, Sias A, Labruna L, Ivry RB (2015b) Nonspecific inhibition of the motor system during response preparation. J Neurosci 35:1067510684. CrossRef Medline

Greenhouse I, Noah S, Maddock RJ, Ivry RB (2016) Individual differences in GABA content are reliable but are not uniform across the human cortex. Neuroimage 139:1-7. CrossRef Medline

Gupta A, Wang Y, Markram H (2000) Organizing principles for a diversity of GABAergic interneurons and synapses in the neocortex. Science 287: 273-278. CrossRef Medline

Hammer J, Pistohl T, Fischer J, Kršek P, Tomášek M, Marusič P, SchulzeBonhage A, Aertsen A, Ball T (2016) Predominance of movement speed over direction in neuronal population signals of motor cortex: intracra- nial EEG data and a simple explanatory model. Cereb Cortex 26:28632881. CrossRef Medline

Hamsher K, Benton AL (1977) The reliability of reaction time determinations. Cortex 13:306-310. CrossRef Medline

Hasbroucq T, Kaneko H, Akamatsu M, Possamaï CA (1999) The timecourse of preparatory spinal and cortico-spinal inhibition: an H-reflex and transcranial magnetic stimulation study in man. Exp Brain Res 124: 33-41. Medline

Heba S, Puts NA, Kalisch T, Glaubitz B, Haag LM, Lenz M, Dinse HR, Edden RA, Tegenthoff M, Schmidt-Wilcke T (2016) Local GABA concentration predicts perceptual improvements after repetitive sensory stimulation in humans. Cereb Cortex 26:1295-1301. CrossRef Medline

Hennequin G, Vogels TP, Gerstner W (2014) Optimal control of transient dynamics in balanced networks supports generation of complex movements. Neuron 82:1394-1406. CrossRef Medline

Hensch TK, Stryker MP (2004) Columnar architecture sculpted by GABA circuits in developing cat visual cortex. Science 303:1678-1681. CrossRef Medline

Herbsman T, Forster L, Molnar C, Dougherty R, Christie D, Koola J, Ramsey D, Morgan PS, Bohning DE, George MS, Nahas Z (2009) Motor threshold in transcranial magnetic stimulation: the impact of white matter fiber orientation and skull-to-cortex distance. Hum Brain Mapp 30:20442055. CrossRef Medline

Hubel DH, Wiesel TN (1962) Receptive fields, binocular interaction and functional architecture in the cat's visual cortex. J Physiol 160:106-154. CrossRef Medline

Johnson MA, Diaz MT, Madden DJ (2015) Global versus tract-specific components of cerebral white matter integrity: relation to adult age and perceptual-motor speed. Brain Struct Funct 220:2705-2720. CrossRef Medline

Kamen G (2004) Reliability of motor-evoked potentials during resting and active contraction conditions. Med Sci Sports Exerc 36:1574-1579. CrossRef Medline

Kandler RH, Jarratt JA, Sagar HJ, Gumpert EJ, Venables GS, Davies-Jones GA, Jordan N (1990) Abnormalities of central motor conduction in Parkinson's disease. J Neurol Sci 100:94-97. CrossRef Medline

Kroeger J, Bäumer T, Jonas M, Rothwell JC, Siebner HR, Münchau A (2010) Charting the excitability of premotor to motor connections while withholding or initiating a selected movement. Eur J Neurosci 32:1771-1779. CrossRef Medline

Kujirai T, Caramia MD, Rothwell JC, Day BL, Thompson PD, Ferbert A, Wroe S, Asselman P, Marsden CD (1993) Corticocortical inhibition in human motor cortex. J Physiol 471:501-519. CrossRef

Labruna L, Lebon F, Duque J, Klein PA, Cazares C, Ivry RB (2014) Generic inhibition of the selected movement and constrained inhibition of nonselected movements during response preparation. J Cogn Neurosci 26: 269-278. CrossRef Medline

Lebon F, Greenhouse I, Labruna L, Vanderschelden B, Papaxanthis C, Ivry RB (2016) Influence of delay period duration on inhibitory processes for response preparation. Cereb Cortex 26:2461-2470. CrossRef Medline

Lefaucheur J-P (2005) Motor cortex dysfunction revealed by cortical excitability studies in Parkinson's disease: influence of antiparkinsonian treatment and cortical stimulation. Clin Neurophysiol 116:244-253. CrossRef

Leocani L, Cohen LG, Wassermann EM, Ikoma K, Hallett M (2000) Human corticospinal excitability evaluated with transcranial magnetic stimulation during different reaction time paradigms. Brain 123:1161-1173. Medline

Maddock RJ, Casazza GA, Fernandez DH, Maddock MI (2016) Acute modulation of cortical glutamate and GABA content by physical activity. J Neurosci 36:2449-2457. CrossRef Medline

Malcolm MP, Triggs WJ, Light KE, Shechtman O, Khandekar G, Gonzalez Rothi LJ (2006) Reliability of motor cortex transcranial magnetic stimulation in four muscle representations. Clin Neurophysiol 117:10371046. CrossRef Medline

Mescher M, Tannus A, Johnson MO, Garwood M (1996) Solvent suppression using selective echo dephasing. J Magn Reson 123:226-229. CrossRef

Mescher M, Merkle H, Kirsch J, Garwood M, Gruetter R (1998) Simultaneous in vivo spectral editing and water suppression. NMR Biomed 11:266272. Medline

Michaels JA, Dann B, Intveld RW, Scherberger H (2015) Predicting reaction time from the neural state space of the premotor and parietal grasping network. J Neurosci 35:11415-11432. CrossRef Medline 
Mikkelsen M, Singh KD, Sumner P, Evans CJ (2016) Comparison of the repeatability of GABA-edited magnetic resonance spectroscopy with and without macromolecule suppression. Magn Reson Med 75:946-953. CrossRef Medline

Miller J, Ulrich R (2013) Mental chronometry and individual differences: modeling reliabilities and correlations of reaction time means and effect sizes. Psychon Bull Rev 20:819-858. CrossRef Medline

Mullins PG, McGonigle DJ, O'Gorman RL, Puts NA, Vidyasagar R, Evans CJ, Edden RA (2014) Current practice in the use of MEGA-PRESS spectroscopy for the detection of GABA. Neuroimage 86:43-52. CrossRef Medline

Near J, Andersson J, Maron E, Mekle R, Gruetter R, Cowen P, Jezzard P (2013) Unedited in vivo detection and quantification of $\gamma$-aminobutyric acid in the occipital cortex using short-TE MRS at 3 T. NMR Biomed 26:1353-1362. CrossRef Medline

Near J, Edden R, Evans CJ, Paquin R, Harris A, Jezzard P (2015) Frequency and phase drift correction of magnetic resonance spectroscopy data by spectral registration in the time domain. Magn Reson Med 73:44-50. CrossRef Medline

O'Gorman RL, Michels L, Edden RA, Murdoch JB, Martin E (2011) In vivo detection of GABA and glutamate with MEGA-PRESS: reproducibility and gender effects. J Magn Reson Imaging 33:1262-1267. CrossRef Medline

Owens DF, Kriegstein AR (2002) Is there more to gaba than synaptic inhibition? Nat Rev Neurosci 3:715-727. CrossRef Medline

Palmer E, Ashby P (1992) Corticospinal projections to upper limb motoneurones in humans. J Physiol 448:397-412. CrossRef

Pascual-Leone A (2003) Transcranial magnetic stimulation in neurology. Lancet Neurol 2:145-156. Medline

Pascual-Leone A, Valls-Solé J, Wassermann EM, Brasil-Neto J, Cohen LG, Hallett M (1992) Effects of focal transcranial magnetic stimulation on simple reaction time to acoustic, visual and somatosensory stimuli. Brain 115:1045-1059. Medline

Pascual-Leone A, Valls-Solé J, Brasil-Neto JP, Cohen LG, Hallett M (1994) Akinesia in Parkinson's disease. I. Shortening of simple reaction time with focal, single-pulse transcranial magnetic stimulation. Neurology 44:884891. CrossRef Medline

Penke L, MuñozManiega S, Murray C, Gow AJ, Hernández MC, Clayden JD, Starr JM, Wardlaw JM, Bastin ME, Deary IJ (2010) A general factor of brain white matter integrity predicts information processing speed in healthy older people. J Neurosci 30:7569-7574. CrossRef Medline

Rosenbaum DA (1980) Human movement initiation: specification of arm, direction, and extent. J Exp Psychol Gen 109:444-474. CrossRef Medline

Rossini PM, Rossi S (1998) Clinical applications of motor evoked potentials. Electroencephalogr Clin Neurophysiol 106:180-194. CrossRef Medline

Rossini PM, Burke D, Chen R, Cohen LG, Daskalakis Z, Di Iorio R, Di Lazzaro V, Ferreri F, Fitzgerald PB, George MS, Hallett M, Lefaucheur JP, Langguth B, Matsumoto H, Miniussi C, Nitsche MA, Pascual-Leone A, Paulus W, Rossi S, Rothwell JC, et al. (2015) Non-invasive electrical and magnetic stimulation of the brain, spinal cord, roots and peripheral nerves: basic principles and procedures for routine clinical and research application. An updated report from an I.F.C.N. Committee. Clin Neurophysiol 126:1071-1107. CrossRef

Rothwell JC (1997) Techniques and mechanisms of action of transcranial stimulation of the human motor cortex. J Neurosci Methods 74:113-122. CrossRef Medline
Schulz H, Ubelacker T, Keil J, Müller N, Weisz N (2014) Now I am readynow I am not: the influence of pre-TMS oscillations and corticomuscular coherence on motor-evoked potentials. Cereb Cortex 24:1708-1719. CrossRef Medline

Stagg CJ, Bachtiar V, Johansen-Berg H (2011a) The role of GABA in human motor learning. Curr Biol 21:480-484. CrossRef Medline

Stagg CJ, Bestmann S, Constantinescu AO, Moreno LM, Allman C, Mekle R, Woolrich M, Near J, Johansen-Berg H, Rothwell JC (2011b) Relationship between physiological measures of excitability and levels of glutamate and GABA in the human motor cortex. J Physiol 589:5845-5855. CrossRef

Starr A, Caramia M, Zarola F, Rossini PM (1988) Enhancement of motor cortical excitability in humans by non-invasive electrical stimulation appears prior to voluntary movement. Electroencephalogr Clin Neurophysiol 70:26-32. CrossRef Medline

Stinear CM, Barber PA, Smale PR, Coxon JP, Fleming MK, Byblow WD (2007) Functional potential in chronic stroke patients depends on corticospinal tract integrity. Brain 130:170-180. Medline

Stokes MG, Barker AT, Dervinis M, Verbruggen F, Maizey L, Adams RC, Chambers CD (2013) Biophysical determinants of transcranial magnetic stimulation: effects of excitability and depth of targeted area. J Neurophysiol 109:437-444. CrossRef Medline

Tamnes CK, Fjell AM, Westlye LT, Østby Y, Walhovd KB (2012) Becoming consistent: developmental reductions in intraindividual variability in reaction time are related to white matter integrity. J Neurosci 32:972-982. CrossRef Medline

Tremblay F, Tremblay LE (2002) Cortico-motor excitability of the lower limb motor representation: a comparative study in Parkinson's disease and healthy controls. Clin Neurophysiol 113:2006-2012. CrossRef Medline

Tremblay S, Beaulé V, Proulx S, De Beaumont L, Marjanska M, Doyon J, Pascual-Leone A, Lassonde M, Théoret H (2013) Relationship between transcranial magnetic stimulation measures of intracortical inhibition and spectroscopy measures of GABA and glutamate+glutamine. J Neurophysiol 109:1343-1349. CrossRef

Tsodyks MV, Skaggs WE, Sejnowski TJ, McNaughton BL (1997) Paradoxical effects of external modulation of inhibitory interneurons. J Neurosci 17:4382-4388. Medline

Valls-Solé J, Pascual-Leone A, Wassermann EM, Hallett M (1992) Human motor evoked responses to paired transcranial magnetic stimuli. Electroencephalogr Clin Neurophysiol 85:355-364. CrossRef Medline

van Vreeswijk C, Sompolinsky H (1996) Chaos in neuronal networks with balanced excitatory and inhibitory activity. Science 274:1724-1726. CrossRef Medline

Waagepetersen HS, Sonnewald U, Schousboe A (2003) Compartmentation of glutamine, glutamate, and GABA metabolism in neurons and astrocytes: functional implications. neuroscientist 9:398-403. CrossRef Medline

Waagepetersen HS, Sonnewald U (2007) 1 Glutamine, glutamate, and GABA: metabolic aspects. In: Handbook of neurochemistry and molecular neurobiology, Chap 1 (Lajtha A, Oja SS, Schousboe A, Saransaari P, eds), pp 1-21. Boston, MA: Springer.

Yoon JH, Maddock RJ, Rokem A, Silver MA, Minzenberg MJ, Ragland JD, Carter CS (2010) GABA Concentration is reduced in visual cortex in schizophrenia and correlates with orientation-specific surround suppression. J Neurosci 30:3777-3781. CrossRef Medline 